\title{
A Educação Positivista Republicana como uma herança cultural e patrimonial da Primeira República na Campanha Gaúcha
}

\author{
The Positivist Republican Education as a cultural and patrimonial heritage of the First Republic in Campanha \\ Gaucha
}

\author{
Alessandro Carvalho Bica \\ Universidade Federal do Pampa - UNIPAMPA - Bagé - Rio Grande do Sul - Brasil
}

\begin{abstract}
Resumo: Este artigo é resultado do desdobramento da tese de doutoramento: $A$ Sistematização da Educação Pública Municipal no Governo de Carlos Cavalcanti Mangabeira (1925-1929) no município de Bagé/RS. Neste sentido, pretendemos estabelecer diálogos historiográficos e narrativas históricas sobre às concepções positivistas estabelecidas e presentes na Educação Republicanano município de Bagé-RS, no período da Primeira República (1889-1930), além de compreender como este pensamento educacional representou o pensamento social e hegemônico de uma época histórica, deixando importantes traços culturais e heranças patrimoniais para a sociedade bageense nas primeiras décadas do século XX. Neste sentido, o olhar dispensado para as fontes utilizadas no corpo deste trabalho ancorou-se pelo prisma da metodologia histórico-crítica, constituindo um arcabouço empírico capaz de articular as relações entre o escrito e o não-escrito dos documentos.
\end{abstract}

Palavras-chave: Educação Republicana. Positivismo. História e Patrimônio Cultural.

\begin{abstract}
This article is the result of the doctoral thesis of unfolding: The systematization Municipal Public Education in the government of Carlos CavalcantiMangabeira (1925-1929) in the city of Bagé/RS. In this regard, we intend to establish dialogues historiographical and historical narratives on the established positivistic ideas and gifts at the Republican Education in the municipality of Bagé-RS, in the period of the First Republic (1889-1930), as well as understand how this educational thought represented the social thought and hegemonic a historical epoch, leaving important cultural traits and heritage legacies for bageense society in the first decades of the twentieth century. In this sense, the look waived for the fonts used in the body of this work was anchored through the prism of historical-critical methodology, and an empirical framework able to articulate the relationship between the written and unwritten documents.
\end{abstract}

Keywords: Republican education. Positivism. History and Cultural Heritage. 


\section{Introdução}

Ao longo da República Velha, o Estado do Rio Grande do Sul viveu uma experiência singular em termos político-administrativos com a ascensão ao poder do Partido Republicano Rio-Grandense, sob o comando e a tutela de Júlio de Castilhos, estabeleceu-se uma filosofia particular aliada a uma prática política ditatorial.

Sendo assim, a Primeira República no Rio Grande do Sul foi marcada pela hegemonia política do Partido Republicano Rio-Grandense, que se manteve no poder tanto na esfera estadual, como no controle do município de Bagé.

Esta atuação foi assinalada pela influência ideológica do Positivismo, o qual, de acordo com Tambara (1991) apresentou certas especificidades, decorrentes da aproximação das ideiasde Auguste Comte com a leitura ideológica realizada por Júlio de Castilhos, este conjugamento ideológico ficou conhecido como Castilhismo ${ }^{1}$.

\footnotetext{
${ }^{1}$ A obra Castilhismo: Uma Filosofia da República escrita por Ricardo Vélez Rodríguez, busca compreender as origens, as influências, os sentidos e os reflexos do Castilhismo, e, resume neste sentido o conjunto de princípios e de regras norteadoras da prática castilhista: A "pureza das intenções", pré-requisito moral de todo governante; $\mathrm{O}$ bem público interpretado como "reino da virtude"; e, o exercício de tutela moralizadora do Estado sobre a sociedade. (2000, p. 17). Ainda, no esforço de compreender o fenômeno do Castilhismo, bem como a incorporação de seus princípios pelos republicanos, Rodríguez (2007, p. 64 e 73-74) faz as seguintes considerações sobre esta ideologia: O principio básico para o Castilhismo é de que a sociedade caminha inexoravelmente para a sua estruturação racional [...]. Quando uma personalidade esclarecida pela ciência social assume o governo, pode transformar o caráter de uma sociedade que levou séculos para se constituir. A ação política de Castilhos inscreveu-se nesse contexto: não consultou a opinião do povo, nem sequer indagou acerca das condições de receptividade do meio para a sua ação, porque, impelido por um móvel poderoso [...] soube aproveitar o concurso dos fatores predominantes e, de acordo com eles, influir nas multidões, sendo por elas seguido de maneira irrefreável. [...] para os Castilhistas a Assembléia Estadual estava composta, indistintamente, por todos os grupos sociais, aglutinados ao redor do Partido Republicano Rio-Grandense, que era imaginado como agremiação partidária única, uma vez que não se tolerava o pluralismo partidário e, muito menos, o funcionamento da oposição. [...] os castilhista davam preferência á renovação política, da qual esperavam a mudança moral e espiritual. [...] no castilhismo há uma tendência unificadora em torno do Estado [...], nota-se a tendência a converter tudo em função estatal [...] no sistema castilhista, o escancarado favorecimento da doutrina estatal, através da imprensa do Partido Único e das perseguições, sem piedade, aos jornais da oposição. Rodríguez, Ricardo Vélez. Castilhismo: Uma Filosofia da República. Brasília: Senado Federal, Conselho Editorial, 2000. (Coleção 500 anos) e Rodríguez, Ricardo Vélez. $\mathbf{0}$ castilhismo $\mathrm{e}$ as outras ideologias: In: Golin, Tau; Boeira, Nelson (Org). História do Rio Grande do Sul. Passo Fundo: Méritos, 2007, v. 3, Tomo I.
}

Portanto, neste processo desencadeado entre o final do século XIX e nas primeiras décadas do século $\mathrm{XX}$, os republicanos programaram um projeto modernizador de ordem capitalista e centrado em um modelo autoritário de poder. Dentro desta perspectiva, os líderes republicanos na condução administrativa do Estado conferiram a escola e ao ensino público, o caminho principal para o êxito do projeto político republicano de educação, isto é, a formação da "consciência nacional" e o estabelecimento do estatuto da cidadania. (Corsetti, 2008.)

Neste esforço pela estruturação do ensino público como meio de intervenção social, os governos republicanos estaduais trataram de pensar e qualificar políticas públicas educacionais para modernizar e renovar a educação estadual. Sobre esta concepção republicana de educação, Corsetti (1998, p. 154), faz a seguinte consideração:

Em termos educacionais, o governo de orientação positivista moveu-se em função de interesses específicos, que previam a utilização da educação como instrumento de modernização. Nesse sentido a ação governamental, além de jogar com a sua política educacional para ampliar o nível de formação dos gaúchos pela diminuição do analfabetismo, entre outros elementos, demonstrou sua compreensão de que a moral e a educação constituíram-se nos principais elementos de garantia da ordem social, amenizadores de conflitos e promotores da acomodação dos indivíduos à sociedade. A escola foi, assim, um dos mecanismos de construção da hegemonia burguesa. Para tanto, a política educacional do Rio Grande do Sul, na Primeira República, conjugou iniciativas governamentais com, sobretudo, o apoio à iniciativa privada. Insistimos, no entanto, que as ações no campo educacional integraram um conjunto mais abrangente de medidas que, na sua totalidade, configuraram o projeto político dos republicanos positivistas para o Rio Grande do Sul.

Sendo assim, a organização do sistema educacional rio-grandense no período da República Velha, constitui-se no aparato necessário para a construção do projeto político educacional republicano, que se traduziu como patrimônio 
educacional e cultural ${ }^{2}$ da Primeira República. Neste sentido,se faz necessário compreender que neste período, o governo do Estado, manteve primordialmente o controle sobre o ensino primário ${ }^{3}$, sendo que a escola secundária esteve quase sempre tutelada pela iniciativa privada. Portanto, estas iniciativas governamentais provocaram alterações à ordem cotidiana das cidades no que tange às questões educacionais.

Desta forma, podemos compreender que a educação pública adquiria uma importância vital, pois seria o único meio natural para aflorar as aptidões individuais e desenvolvê-las de forma conveniente. Para Nagle (2001), foi diante deste quadro de transformações ocorridas conjuntamente com os setores da economia, da política, da sociedade e da cultura, que se deve analisar o processo da expansão do ensino. Este esforço deve ser analisado e julgado em combinação com os demais elementos da cultura brasileira, e com as condições da existência social definidas na exposição dos setores político, econômico e social.

O processo da evolução das ideiaspedagógicas na Primeira República pode ser caracterizado pela expansão da escolarização como

\footnotetext{
${ }^{2}$ Entendemos a concepção de patrimônio, a partir dos estudos de Chuva (2008, p.31), onde: está relacionada ao seu papel na formação de grupos de identidade, isto é, associada a práticas voltadas para o fortalecimento dos laços de identidade de determinados grupos e de sua afirmação enquanto tal. Neste sentido, a ideia de Patrimônio Educacional e Cultural é compreendida por todas as intervenções administrativas e/ou políticas públicas que promoveram mudanças educacionais e que deixaram heranças significativas para os grupos sociais envolvidos e que de alguma forma incorreram em práticas culturais diferenciadas destes grupos através dos tempos.

${ }^{3}$ Em relação à organização do sistema educacional no Estado do Rio Grande do Sul, se faz necessário mencionar os artigos presentes na Constituição Estadual de 1891, que tratam especificamente sobre a questão do ensino no Estado. Em relação às atribuições do Presidente do Estado sobre à educação, encontra-se o artigo 25 - Providenciar sobre o ensino público primário, gratuito e livre, ministrado pelo Estado; e, em relação às garantias encontradas pelos habitantes do Estado em relação ao ensino, encontra-se o Art. 71 - 10 - Será leigo, livre e gratuito o ensino primário ministrado nos estabelecimentos do Estado. (ESTADO DO RIO GRANDE DO SUL. Constituições sul-rio-grandenses (1843-1947). Porto Alegre: Imprensa Oficial, 1963. Disponível em:

http://www2.al.rs.gov.br/memorial/LinkClick.aspx?fileticket=frKwl dvbn2g\%3D\&tabid=3456\&language=pt-BR. Acesso em 02/06/2013). Sobre a função da escola para os republicanos riograndenses, Carboni e Maestri (2000), afirmam que ela possuía duas funções: ser alavanca para desenvolvimento e aparato privado da hegemonia. CARBONI, Florence; MAESTRI, Mário (org.) Raízes italianas no Rio Grande do Sul (1875-1987). Passo Fundo: UPF, 2000.
}

grande instrumento para a construção da participação política. Sobre este período Saviani (2008, p.177) traz o seguinte comentário:

Em suma, as primeiras décadas do século $X X$ caracterizavam-se pelo debate de idéias liberais sobre cuja base se advogou a extensão universal, por meio do Estado, do processo de escolarização, considerado o grande instrumento de participação política. É, pois, a idéia central da vertente leiga da concepção tradicional, isto é, a transformação, pela escola, dos indivíduos ignorantes em cidadãos esclarecidos, que esteve na base do movimento denominado por Nagle (1974) de "entusiasmo pela educação", o qual atingiu seu ponto culminante na efervescente década de 1920.

Portanto no processo de reconstrução da história das políticas públicas educacionais pensadas e/ou realizadas pelos intendentes municipais nas duas primeiras décadas do século $X X$, subsidiamos nossas análises com base nos Relatórios Intendenciais, Relatórios de Orçamento e notícias veiculadas pelos periódicos editados na cidade de Bagé.

Neste sentido, entendemos que os Relatórios ${ }^{4}$ Intendenciais ${ }^{5}$ e Orçamentais são fontes de pesquisa, e, eram produzidos geralmente no mês de setembro, possuíam como objetivo apresentar o mapeamento das ações e programas realizados pelo Intendente Municipal, referentes a todos os campos da administração pública. Na feitura destes relatórios, cada assunto da administração pública possuía um

\footnotetext{
4 A feitura, a apresentação e a leitura dos Relatórios Intendenciais realizada pelos Intendentes municipais aos Conselheiros do município, ocorria geralmente entre os meses de setembro ou outubro, e fazia parte de todo um aparato simbólico e ideológico pensado pelos republicanos, que buscava representar à lisura, a honestidade, a integridade e a boa fé dos administradores sobre as questões do gerenciamento da coisa pública. Esta concepção foi uma prática realizada pelos positivistas, durante toda a Primeira Republica no Estado do Rio Grande do Sul, e pode ser definida pela frase: "Viver para Outrem, Viver às Claras". Sobre este assunto, consultar: CORSETTI (1998) e GUTFREIND (1998).

5 Os relatórios intendenciais, sejam eles, os encontrados no jornal O Dever ou os próprios editados pela Intendência, não contemplam e/ou completam a série total das primeiras décadas do século $X X$, sendo assim, dispomos apenas dos relatórios dos seguintes anos: 1903 a 1908; 1910; 1914 a 1918; 1920 a 1922 e de 1924 a 1930. Portanto, na escrita deste capítulo, as análises serão feitas na conjunção dos dados encontrados nos relatórios intendenciais e orçamentários do município de Bagé.
} 
espaço específico para o relato das atividades anuais do Intendente e seus secretários.

Sendo assim, os esforços estaduais empreendidos pelo governo no processo de expansão do ensino desde a instauração da república no Estado do Rio Grande do Sul, também foram acompanhados pelos intendentes republicanos nas principais cidades do Estado. Nesta perspectiva, é importante perceber e analisar como se planejaram as políticas públicas ${ }^{6}$ para a educação municipal nas primeiras décadas do século $X X$, na cidade de Bagé.

Os primeiros relatos dos esforços municipais em tentar resolver os problemas educacionais vividos pelo município podem ser observados nas notícias do jornal "O Dever" de 19 de novembro de 1901:

O benemérito intendente Major José Octavio Gonçalves que não mede sacrifícios quando se trata da difusão escolar deste município, poz á disposição do Governo, um edifício para nelle funcionar o Collegio Districtal. O Estado facultando a educação, ás creanças que mais tarde serão os seus deffensores, os seus sustentáculos, alguns chefes e guias, e todos elles o objecto de seu legitimo orgulho, continua a dar salutares exemplos ao resto do Brasil. Não é só por ser o modelo da justiça, da prudencia, do desinteresse, da moderação, que o Governo do Estado tornou-se tão firme e poderoso; por ter consolidado todas as forças moraes, materiais e politicas da sociedade é, mais ainda, porque ama e proteje - a Instrução. (O Dever, 19/11/1901, p. 03)

\footnotetext{
${ }^{6} \mathrm{Na}$ perspectiva de compreender e/ou conceituar políticas públicas para a educação, compreende-se que as políticas educacionais se situam no âmbito das políticas públicas de caráter social, sendo assim, não são estáticas, mas dinâmicas, ou seja, estão em constante transformação. Para compreendêlas, é necessário entender o projeto político do Estado, em seu conjunto, e as contradições do momento histórico em questão. Sobre as preocupações que os pesquisadores devem tomar no processo de análise e compreensão das políticas públicas, Saviani (1986, p.135), traz o seguinte alerta: Para se compreender o real significado da legislação não basta ater-se à letra da lei; é preciso captar o seu espírito. Não é suficiente analisar o texto; é preciso examinar o contexto. Não basta ler nas linhas; é necessário ler nas entrelinhas. Neste sentido, o conceito de Políticas Públicas comporta várias significações. Para alguns, pode ocorrer uma redundância, visto que toda política, pela própia natureza etimológica da palavra é essencialmente pública. Este termo pode referir-se a diferentes áreas ou campos de atuação governamental, por exemplo política econômica, políticas sociais, ou ainda, ambientais. Pode remeter aos processos próprios da ação política, no que diz respeito aos instrumentos, regras e organização das forças que se enfrentam ou se articulam no espaço dos embates. Pode significar, ainda, as instituições políticas, como o Estado e suas normas, regras e marcos jurídicos. Sobre este assunto, consultar: AZEVEDO, Janete M. L. A educação como política pública. Campinas, SP: Autores Associados, 1997.
}

Outra afirmação que se pode aferir desta nota, é o papel destinado ao Governo Estadual, numa relação co-participe das responsabilidades sobre a Educação Primária Municipal. Ainda sobre a Instrução Pública ${ }^{7}$ na cidade de Bagé, encontramos no Jornal $O$ Dever de 28 de novembro de 1901:

De pessoa competente recebemos os seguintes dados, [...] Das 8 aulas existentes nesta cidade, 7 funccionaram durante todo 0 anno lectivo. Em quase todas as aulas, sobraram livros e utensilios fornecidos pelo Estado, para serem distribuidos pelos alumnos, os quaes receberam dos respectivos professores, tudo o que foi necessário para o ensino. As aulas foram inspeccionadas por diversas vezes, pelo respectivo Inspector Regional, que encontrou sempre, em todas, numero de alumnos muito superior ao que exige o Regulamento da Instrucção publica. Finalmente, todas as aulas funccionaram em prédios confortáveis [...]. (O Dever, 28/11/1901, p. 02)

Nesta notícia do jornal O Dever, observamos a preocupação em demonstrar um inventário detalhado sobre as estatísticas e condições escolares encontradas na cidade de Bagé. No Relatório Intendencial, publicado em $01^{\circ}$ de setembro do ano de 1903, apresentado pelo Secretário Municipal Pedro Antonio da Cunha ao Intendente Municipal Major José Octavio Gonçalves no que se refere à instrução municipal, notamos as primeiras contradições e incongruências entre o pensado pela municipalidade e as reais características municipais da educação. Deste Relatório, retiramos o seguinte excerto sobre a Instrução Pública Municipal:

\footnotetext{
7 Entendemos Instrução Pública Municipal como uma atividade organizada e promovida pelo poder público. Neste sentido, ao usarmos esta expressão, estamos nos referindo ao conjunto das ações educacionais encontradas nos Relatórios Intendenciais. Neste sentido, na perspectiva de diferenciar a Instrucão Pública Municipal da Educacão Pública Municipal, definimos que enquanto Instrução Pública Municipal representa toda a oferta do ensino escolar no município, seja ele, municipal, estadual ou privado; por outro lado, a Educacão Pública Municipal, se refere somente ao conjunto isolado das ações educacionais da administração municipal. $\mathrm{Na}$ elaboração desta definição, usamos como subsídio teórico os seguintes textos: CONDERCET, M. J. A. N. Cinco memorias sobre la instrucción pública e otros escritos. Madrid: Morata, 2011; LUZURIAGA, L. História da educacão pública. São Paulo: Editora Nacional, 1959 e MAGALHÃES, Justino Pereira de.A construção de um município pedagógico - o caso de Vimioso. Lisboa: Universidade de Lisboa, 2004 (mimeo).
} 
As aulas municipaes localisadas no $5^{\circ}$ e $6^{\circ}$ districto, funccionam com regularidade, não correspondendo, infelizmente, a frequencia de alumnos, as despezas que o municipio faz para mantel-as. É sabido a insistência com que foram requeridas as creações dessas aulas pelos moradores desses districtos; no entretanto, nas epocas de preparos de terra e plantações, as creanças abandonam por completo a instrucção para se entregarem a esses labores, afim de auxiliarem os seus progenitores! Em 24 de março deste anno foi inaugurado oficialmente o collegio districtal no prédio á praça Coronel Telles e em que funcionára a sede do governo do municipio. Apezar de já terem requerido matricula cento e tantos alumnos,este importante estabelecimento de instrucção ainda não abriu as suas aulas, pela falta de moveis, que estão sendo esperados de Porto Alegre. Neste sentido já tomastes as necessárias providencias, sendo possível que brevemente elle comece a funcionnar. (grifos nossos) (Relatório Intendencial de 1903, p.05)

Através deste Relatório Intendencial análises iniciais podem ser feitas, sobre as reais condições das aulas municipais na cidade de Bagé, tais como: -

A preocupação com as despesas originadas pela manutenção das aulas municipais - $A$ existência de aulas franqueadas pelo município nos arrabaldes da cidade tinha que disputar espaços sociais com as atribuições cotidianas impostas pelas ainda características rurais da cidade; - Os esforços estaduais conjuntamente com os municipais em prover o município de um Colégio Distrital ${ }^{8}$ esbarravam nas questões de infra-estrutura de responsabilidade do Estado;

Estas ações empreendidas pela municipalidade e amparadas pelo discurso modernizador do governo estadual, tinham como

\footnotetext{
${ }^{8}$ Os Colégios Distritais foram instituídos no Estado do Rio Grande do Sul pelo Decreto o 82, de 02 de fevereiro de 1897, que reorganizou a Instrução Primária no Estado, neste sentido. Estes colégios tinham como objetivo difundir e desenvolver o ensino primário e eram classificados em dois tipos: Distritais e Elementares. O Colégio Distrital da cidade de Bagé foi instituído pelo Decreto no 604 de 09 de março de 1903 e dissolvido pelo Decreto no 836 de 18 de novembro de 1905, pois não atendia os objetivos para o qual havia sido criado. Segundo nota do jornal O Dever de $1^{\circ}$ de fevereiro de 1903 (p.02), as aulas no Colégio Distrital começariam no dia 15 de fevereiro de 1903, sob a direção de Affonso Machado Coelho, e dos professores João Roque Moreira Gomes para a Classe Elementar masculina, Maria Clara Mogetti para a Classe Elementar feminina, Angelica de Vilhena Cardoso para $1^{\underline{a}}$ Classe Complementar feminina e Affonso Machado Coelho para a $1^{\text {a }}$ Classe Elementar Masculina.
}

pressuposto tornar a escola pública instrumento primordial na configuração da política do Estado gaúcho, que tinha como objetivo, a modernização, a garantia da estabilidade e o controle social.

As constantes preocupações dos Intendentes municipais em relação à deficiência do sistema educacional da cidade são verificadas na seqüência de descrições encontradas nos Relatórios Intendenciais do município de Bagé. No Relatório Intendencial referente ao ano de 1905, publicado no jornal O Dever de 28 de outubro do mesmo ano, pelo Intendente Augusto Lucio de Figueiredo Teixeira, percebemos o panorama da Educação Pública Municipal:

\begin{abstract}
Instrucção Publica - É notavel a deficiencia de escolas na campanha do municipio. De todos os districtos tenho recebido pedidos para a creação de estabelecimentos de ensino publico, ponderando-me os interessados que existe grande numero de analphabetos nos nossos departamentos ruraes, verdade que infelizmente não admitte contestação. Aferindo-me pelo grau de instrucção, o progresso dos povos, é obvio que ella nos deve merecer os maiores cuidados. Existe no 5 districto uma aula municipal sob a regência do professor Manoel Pantaleão da Cunha, e outra no $6^{\circ}$, sob a direcção do professor Appolinario Ferreira dos Passos. Julgo, porém, indispensavel a dotação a cada districto de uma aula municipal. Se assim o entenderdes e quizerdes devereis ter presente que a aula do $1^{\circ}$ districto será localisada fóra da zona sub-urbana, no Pirahysinho, onde a agglomeração de operários das duas xarqueadas ali existentes, faz presuppor um importante nucleo de população escolar. $\mathbf{0}$ Estado mantem funccionando nesta cidade, oito escolas, inclusive o Collegio Districtal, installado em um proprio do Municipio. Além destas prestam ainda o seu concurso á instrucção primaria e secundaria, entre nós, onze aulas particulares, distribuídas todas dentro dos limites urbanos e suburbanos, entre as quaes se comprehende o collegio N. S. Auxiliadora, dirigido por padres salesianos, instituto de ensino que veio satisfazer uma grande e legitima aspiração do nosso povo. (grifos nossos) (O Dever, 28/10/1905, p. 02)
\end{abstract}

Do Relatório apresentado acima, podemos concluir que nas iniciativas municipais em relação ao ensino primário, incorriam os seguintes problemas, a permanência numérica de poucas escolas na região da campanha do município, o grande número de 
analfabetos na cidade e a necessidade de criação novas aulas nos distritos municipais. Neste sentido também, verifica-se uma eficácia maior na oferta de aulas tuteladas pelo governo do Estado, num total de 08 (oito) aulas e mais um Colégio Distrital, e uma efetiva participação da iniciativa privada na constituição de 11 (onze) escolas e/ou aulas no município.

Corsetti (2008) afirma que durante a Primeira República, o Estado do Rio Grande do Sul experimentou uma participação ativa da iniciativa privada no estabelecimento de instituições escolares, sendo possível perceber nos discursos republicanos, as garantias concedidas para a iniciativa privada em manter e ampliar seus espaços de penetração nos negócios da educação.

Durante o governo de Augusto Lúcio de Figueiredo Teixeira observam-se as primeiras tentativas de expansão do ensino primário municipal, bem como, a preocupação na redução do analfabetismo que atingia taxas altíssimas no município de Bagé, logo se percebe que a educação constitui-se na principal ferramenta republicana. Estas constatações podem ser observadas no Relatório Intendencial do ano de 1906:

Instrucção Publica - Logo no começo do anno, foi supprimido o collegio districtal, que sob a digna direcção do sr. Professor Affonso Machado Coelho, mantinha o nosso patriotico governo estadual. Continuam a funccionar 6 aulas publicas estaduaes; sendo 03 mixtas, duas do sexo feminino e uma do masculino, com frequencia de 366 alumnos, sob a competente inspecção do professor sr. Azambuja Netto, ilustre educacionista ultimamente nomeado para esta zona escolar. Em meu anterior relatorio, tive ensejo de patentear-vos a deficiência de escolas na campanha, onde é enorme o numero de analphabetos. Usando verba que para esse fim decretastes, creando mais quatro escolas, quando apenas existiam duas, localisei no populoso logar denominado Pirahyzinho, nas immediações das xarqueadas, uma aula sob a direcção da senhorita Marina Mogetti, que com proficiência tem se entregado aos árduos labores de seu cargo. Seria para desejar que nas xarqueadas, à margem do Quebracho, fosse creada uma outra escola, em vista tambem de ser ali numerosa a população escolar. Foram nomeadas para reger as do 3 e $4^{\circ}$ districto as exmas sras. d. d. Maria Annunciação Martins Lopes e Maria
Magdalena Lucas Collares, as quaes têm revelado zelo e competencia nos mysteres de sua profissão. Para 0 60 distrito foi escolhido o sr. Beltrão Osório de Castro, continuando como professor no $5^{\circ} \mathrm{o}$ sr. Manoel Pantaleão da Cunha, funccionarios esses merecedores de francos elogios. A frequencia de nossas aulas da campanha é de 106 alumnos, sendo 87 do sexo masculino e 19 do feminino. (grifos nossos) (O Dever, 18/10/1906, p.01)

Sobre as considerações descritas no Relatório Intendencial das condições da educação primária municipal percebe-se às seguintes questões: a nomeação de professoras municipais para as aulas públicas, a extinção do Colégio Distrital e que apenas 06 (seis) aulas estaduais estavam providas. Quanto à participação da iniciativa privada, observa-se 0 destaque dado à presença de duas instituições de ensino católicas na cidade, o Ginásio Nossa Senhora Auxiliadora para o sexo masculino e o Colégio Franciscano Espírito Santo destinado a educação das meninas.

Os Relatórios Intendenciais apresentados nos anos de 1907 e 1908, pelo Intendente municipal, Augusto Lucio de Figueiredo Teixeira ${ }^{9}$ ao Conselho Municipal, retratam o panorama da Instrução Pública no município, além de apontar transformações ocorridas em termos educacionais em sua gestão intendencial:

Instrucção Publica - São seis as aulas municipaes creadas para dar instrucção a grande numero de nossos municipaes que d'ella tanto precizam.[...] Alem das seis a que me refiro existem mais 12 escolas estaduaes e 13 collegios particulares[...]. Brevemente, em fevereiro talvez, será inaugurada em uma das sachristias da nossa Igreja Matriz, uma aula para meninos pobres e desprotegidos, obra grandiosa do nosso vigário ver. Hyppolito Costabile, que alli á sua extrema bondade e cordura, uma superior força de vontade. Frequentou todos os collegios que vos citei, o

\footnotetext{
9 No processo empírico da pesquisa, percebeu-se a ausência do Relatório Intendencial relativo ao ano de 1909, esta constatação tem relação direta aos decretos de nำ1450, de 23 de março de 1909, que anulou a Eleição do Conselho Municipal e ao decreto de o 1459 , de 11 abril de 1909 que nomeou como Intendente Juvêncio Maximiliano Lemos, em virtude das irregularidades ocorridas no processo eleitoral de 11 de fevereiro de 1909. O novo intendente foi empossado em 15 de abril de 1909, pelo Presidente do Estado do Rio Grande do Sul, Carlos Barbosa permanecendo no governo até 03 de outubro de 1910, e, portanto não apresentou relatório intendencial ao Conselho Municipal, tendo em vista os problemas eleitorais que ocorreram em função das eleições para o Conselho.
} 
numero já elevado de 1612 alummnos, sendo 907 do sexo masculino e 705 do feminino, havendo matriculados mais 4174 do que no anno anterior.Orgulho me em ministrar-vos essas informações que attestam o progresso crescente que nesse particular, faz o nosso caro municipio. (grifos nossos) (O Dever, 05/11/1907, p. 01)

Instrucção Publica - No relatorio anterior vos comunicava que não era a desejada a frequencia de algumas escolas municipaes. Devido á falta de frequencia extingui a escola de $4^{\circ}$ Distrito, cuja professora não podia mudar-se para lugar onde houvesse população escolar que justificasse a despeza que faria o municipio com essa aula. Pediu demissão a professora do $3^{\circ}$ districto. Como fizesse falta uma escola na xarqueada "São Martin" por haver ahi uma grande agglomeração de população, tranferi para lá a escola do $3^{\circ}$ districto e nomeei o sr. Pedro Menezes, que se tem dedicado com zelo ao seu mister. Na xarqueada "Santa Thereza" localisei a aula do $1 \stackrel{0}{ }$ districto a cargo da professora d. Marina Mogetti, a qual tem uma boa frequencia. [...]. Além d'estas, subvencionei com 50\$000 mais duas, uma no Passo do Salso e outra no Quebraxo, ambas no $5^{\circ}$ districto. Existem no municipio mais 11 escolas estaduaes, [...] e 14 collegios particulares. [...]. A matricula total é de 1906 alumnos, sendo 1153 do sexo masculino e 753 do feminino, havendo 294 mais do que no anno estatistico anterior. (grifos nossos) (O Dever, 14/10/1908, p. 01)

Em relação aos dados estatísticos descritos anteriormente nos relatórios intendenciais, podemos compor o seguinte quadro comparativo sobre o panorama das mudanças na Instrução Pública no município de Bagé entre os anos de 1903 e 1908.

Quadro 01 - Panorama Educacional da década de 1900

\begin{tabular}{l|c|c}
\hline Ano & Aulas Municipais & Aulas Estaduais \\
\hline 1903 & 02 & 08 \\
\hline 1904 & 02 & 08 \\
\hline 1905 & 03 & 08 \\
\hline 1906 & 06 & 06 \\
\hline 1907 & 06 & 12 \\
\hline 1908 & 08 & 11 \\
\hline 1909 & Não contam dados & Não contam dados \\
\hline
\end{tabular}

\begin{tabular}{l|c|c|}
\hline Ano & $\begin{array}{c}\text { Aulas } \\
\text { Particulares }\end{array}$ & Frequencia Média \\
\hline $\mathbf{1 9 0 3}$ & Não contam dados & Não contam dados \\
\hline $\mathbf{1 9 0 4}$ & 13 & 1173 alunos \\
\hline $\mathbf{1 9 0 5}$ & 11 & Não contam dados \\
\hline $\mathbf{1 9 0 6}$ & 11 & Não contam dados \\
\hline $\mathbf{1 9 0 7}$ & 13 & 1612 alunos \\
\hline $\mathbf{1 9 0 8}$ & 14 & 1906 alunos \\
\hline $\mathbf{1 9 0 9}$ & Não contam dados & Não contam dados \\
\hline
\end{tabular}

Fonte: Livre adaptação dos dados encontrados nos Relatórios Intendenciais

A partir destes dados, observa-se um crescimento numérico vertiginoso no concurso do estabelecimento da educação primária pela ação municipal, de 02 aulas para 08 aulas, isto significa afirmar que este crescimento alcançou $75 \%$ no número das aulas municipais. Em relação às aulas franqueadas pelo Estado, o crescimento alcançou um índice de $36 \%$, e no que tange a ação da iniciativa privada, este crescimento foi de apenas $7 \%$ no número de aulas e/ou colégios em relação ao início da década.

Outra relação quantitativa que pode ser destacada se traduz no aumento de $28 \%$ nas matrículas do conjunto total das aulas distribuídas no município de Bagé.

Neste sentido, faz necessário também enfatizar que no processo de expansão do ensino primário em Bagé, este foi atendido tanto pela ação municipal como pela iniciativa estadual e privada, mas em relação ao ensino secundário, houve somente a presença de instituições escolares vinculadas às ordens religiosas e/ou particulares na primeira década do século XX.

Por outro lado, nos Relatórios apresentados durante os anos de 1907 e 1908, ainda observamos algumas especificidades no processo de expansão do ensino primário e secundário no município de Bagé. Neste sentido, percebemos claramente a iniciativa do controle da gestão dos recursos humanos e financeiros do município, a efetiva preocupação na apresentação do quadro estatístico educacional e o apreço dado à ação benemérita da Igreja Católica e das ordens confessionais no campo da instrução municipal. 
Portanto, no delineamento da educação gaúcha no período da Primeira República, essa "ação benemérita" da Igreja Católica refletiu-se diretamente na ausência da atuação do Estado junto ao ensino secundário e conseqüentemente no ensino superior, garantindo amplo espaço para a iniciativa privada confessional. No entanto, no que se refere às relações entre Estado e Igreja e no estabelecimento do ensino primário, Corsetti (1998, p. 60) lembra que:

\begin{abstract}
Em paralelo, a política educacional republicana incluiu, através de uma acomodação de interesses, um relacionamento importante entre o PRR e a Igreja Católica que, mesmo não isento de divergências,serviu à concretização dos projetos por eles desenvolvidos. $O$ apoio da Igreja foi elemento relevante no processo de dominação republicana no Rio Grande. Por outro lado, o favorecimento à Igreja, oportunizado pelos republicanos, facilitou a recomposição da posição pretendida pela instituição, que atravessava crise expressiva desde o século XIX, particularmente com a implantação da República e a separação entre Estado e a Igreja. [...]. A disputa com a Igreja, no campo do ensino primário sinalizou que o Estado não abria mão de ser o educador por excelência do trabalhador que o capitalismo necessitava para sua consolidação e pleno desenvolvimento. Não foi por outra razão que o Estado investiu de forma expressiva no ensino primário e foi nesse nível que [...] se concretizou sua preponderância no setor. A Igreja, por seu lado, teve presença predominante no ensino secundário.
\end{abstract}

Dentre todas as ponderações destacadas por Corsetti (1998), a acomodação dos interesses republicanos e católicos, o conciliamento das divergências entre ambas as instituições e a harmonização das relações do PRR com a Igreja, foi um processo extremamente importante na consecução do projeto republicano. Este movimento pode ser observado na carta de Borges de Medeiros endereçada ao Intendente Municipal de Bagé, José Octávio Gonçalves sobre a figura do Padre Hypólito Constabile em 10 de março de 1906:

Palácio do Governo, em Porto Alegre, 10 de março de 1906

llustre amigo sr. Coronel José Octavio Gonçalves.
Bagé.

Tenho a satisfação de apresentar-vos o distincto Hypolito Costabile, que foi provido na vigaria dessa freguesia. Não só pelas apreciaveis qualidades que tem revelado como sacerdote e tambem pelo facto de ser nosso esforçado correligionário, recomendo o ao vosso carinhoso acolhimento, certo de que lhe prestareis os serviços de que venha a necessidade para bem desempenhar-se das suas funcções. Saudo-vos cordialmente.

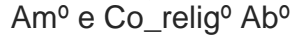

Borges de Medeiros. (grifos nossos) (Fonte: Acervo Museu Dom Diogo de Souza)

É preciso ter em mente que as análises realizadas acima com base nos Relatórios Intendenciais, tem como objetivo esboçar o quadro e o panorama da educação no município, bem como, indicar o processo de expansão educacional que se desencadeou com o iniciar dos anos 1900 na cidade de Bagé. Ademais, este processo ocorrido na primeira década do século $X X$ representa os primeiros passos para consolidação do projeto modernizador republicano no Estado do Rio Grande do Sul.

É importante perceber que apesar dos discursos da municipalidade em aferir a escola o papel de espaço norteador da direção intelectual e moral dos indivíduos, capaz de constituir uma sociedade onde a anarquia fosse suplantada pela ordem e pela prosperidade, desenvolvendo o senso do dever, de obediência e de modernidade da República, as dificuldades encontradas na primeira década do século $X X$ provocariam mudanças substanciais nas décadas seguintes na cidade de Bagé.

Paralelamente aos discursos da municipalidade, os problemas eleitorais ocorridos no ano de 1909, com o pleito eleitoral para o Conselho Municipal $^{10}$, foram resolvidos com a eleição do histórico republicano José Octavio Gonçalves, representante da primeira geração de republicanos e chefe supremo do PRR em Bagé em outubro de 1910, esta eleição "distencionou" o plano político de oposições na cidade, pois sua vitória representava a

\footnotetext{
${ }^{10}$ Sobre este assunto, consultar especificamente a nota de rodapé anterior.
} 
força hegemônica do discurso e das práticas republicanas desde o final do século $\mathrm{XIX}^{11}$.

Apesar dos francos esforços municipais desencadeados na primeira década do século $X X$, em expandir e apoiar a constituição de espaços educativos, estes eram insuficientes para a organização de uma estrutura ${ }^{12}$ do Sistema Educacional Municipal, tendo em vista, que ainda não havia uma legislação municipal ${ }^{13}$ que estruturasse a Educação Pública Municipal no município de Bagé.

$\mathrm{Na}$ perspectiva de organizar o panorama educacional do município de Bagé, na última gestão de José Octavio Gonçalves (1910-1913), lançamos mãos de alguns dados encontrados no Relatório Intendencial municipal conjuntamente com os Relatórios da Instrução Pública do Estado do Rio Grande do Sul neste período.

Em seu primeiro Relatório, José Octavio Gonçalves elabora um inventário detalhado da situação educacional do município de Bagé, apresentando a importância da disseminação e as vantagens do ensino no contexto republicano.

Instrucção Publica - É desnecessario fazer considerações sobre este ramo da

\footnotetext{
11 Cabe salientar, que José Otávio Gonçalves havia sido Intendente municipal entre os anos de 1897 e 1905, período em que ocorreu a afirmação política do PRR e o gradual enfraquecimento das oposições federalistas na cidade.

${ }_{12}$ Os estudos de Saviani (1983) e (2010) nos fazem entender o significado da expressão "estrutura do sistema educacional", na perspectiva de conceituar o termo, Saviani (2010, p. 06) comenta que: [...] estrutura implica a própria textura da realidade; [...], independentemente do homem e, [...]. O sistema, em contrapartida, implica uma ordem que o homem impõe à realidade. Portanto, o homem sofre a ação das estruturas, mas, na medida em que toma consciência dessa ação, ele é capaz de manipular a sua força agindo sobre a estrutura de modo a Ihe atribuir um sentido.

${ }^{13}$ Durante a Primeira República no Estado do Rio Grande do Sul, os republicanos estabeleceram uma série de decretos e regulamentos para a organização do ensino público estadual, e, conseqüentemente no aprimoramento da Instrução Pública no Estado. A pesquisadora Berenice Corsetti em sua tese de doutorado "Controle e Ufanismo: A Escola Pública no Rio Grande do Sul (1889-1930) elabora um interessante quadro sobre todas as legislações relativas ao processo de organização do ensino público estadual ocorrido na Primeira República e defende a seguinte idéia, Corsetti (1998, p. 285286): A organização do ensino público [...] foi promovida através da utilização do instrumento privilegiado pelos positivistas, ou seja, a lei. [...] Devemos ressaltar que essas regulamentações expressaram, [...] pressupostos políticos e educacionais defendidos pelos republicanos. Por outro lado, os estudos e pesquisas realizados sobre o mesmo período político, revelam que a ação da esfera municipal no processo de regulamentação da educação primária, ocorreu somente após a década de 1920 nos municípios do Rio Grande do Sul.
}

administração publica porque todos sabeis as vantagens que dimanam para o paiz, da disseminação do ensino. É a base do progresso de um povo, em todas as manifestações da sua actividade. O governo do Estado a quem especialmente cumpre prover a instrucção, tem procurado melhoral-a n'esta circumscripção como lhe é possivel. $\mathbf{0}$ municipio porêm attenta a insifficiencia de aulas publicas e de acordo com a verba [... inelegível ...], conta actualmente com 5 aulas municipaes, trez das quaes são apenas subvencionadas e todas com uma frequencia de cento e quarenta e cinco alumnos. [...]. O nosso prospero municipio com uma população approximada a $40 \mathrm{mil}$ habitantes, ainda resente-se da falta de instrucção mas, nutre fundadas esperanças na acção proveitosa do patriotico governo do Estado no sentido de melhora-la, como se vae observando das medidas ultimamente adoptadas. (grifos nossos) (O Dever, 23/09/1910, p. 01)

A leitura do Relatório Intendencial, nos relata o cenário da educação municipal, porém, é perceptível neste discurso a ausência de políticas públicas e a insuficiência de aulas tuteladas pelo município, por outro lado, ainda persiste a ação da iniciativa privada nas questões educacionais e o irrestrito apoio à ação estadual no propósito de criação do Colégio Elementar $^{14}$ na cidade de Bagé. Neste sentido, não podemos deixar de fazer alusão a alguns dados estatísticos descritos na obra Apontamentos Históricos e Estatísticos de Bagé de Jorge Reis, encarregado da Estatística do Município. Sobre a Instrução Pública, comenta Reis (1911, p. 67):

Existem funccionando n'esta cidade e
municipio 26 aulas, sendo 13 collegios
particulares, com uma frequencia de 965
alumnos; [...] D'estes, 5 de instrucção primaria
e secundaria. A maior frequencia é a do
colllegio Salesiano, com um numero de 286 ,
seguindo-se o habilmente dirigido pelo sr.
tenente coronel Arthur da Silva Lopes, com

\begin{abstract}
${ }^{14}$ As Metamorfoses do Professorado Gaúcho ao final da República Velha no Rio Grande do Sul é um interessante estudo desenvolvido por Tambara e publicado no II Seminário de Pesquisa em Educação - Região Sul (AnpedSul), ocorrido no ano de 1999 na cidade de Curitiba/PR. Tambara anuncia em seu trabalho, que nos Colégios Elementares presentes no Rio Grande do Sul, os diretores eram quase sempre homens e conseqüentemente os únicos homens da Escola, e que eram raros os estabelecimentos escolares onde houvesse homens trabalhando na função de docente. Em relação ao Colégio Elementar de Bagé, observou-se que a direção deste estabelecimento ficou a cargo do Professor Francisco Pinto de Azambuja Netto até o ano de 1913, que logo após, foi substituído pela Profa Universina de Araújo Bastos que ficou no cargo até o fim da República Velha.
\end{abstract}


160 e o Espirito Santo, com 150. Aulas estaduaes de 1a. Entrancia, providas existem 7, com uma frequencia de 355 alumnos [...]. De $2^{\mathrm{a}}$. entrancia, $2 \mathrm{com}$ uma frequencia de 189 alumnos [...]. O collegio Elementar, dirigido pelo sr. capitão Francisco Pinto de Azambuja Netto, que é auxiliado por 3 professoras e um professor tem uma frequencia de 166 alumnos [...] Aulas municipaes, 4, localisadas nas xarqueadas S. Thereza, S. Martin, estação de S. Rosa e no 3 - Distrito. Frequencia dessas aulas, 136. [...] Total dos alumnos matriculados em todas as aulas do municipio 1.791; sexo masculino 1017, feminino 774 . É presidente do conselho escolar, o Major Julio Soares de Mello. (grifos nossos)

Através destes dados estatísticos, podemos fazer algumas deduções, que apesar das aulas presentes no município de Bagé apresentarem uma matrícula total de 1791 alunos, apenas 1456 alunos ou $81 \%$ destes freqüentavam as cadeiras escolares.

Em relação à frequencia verificada no total das aulas, podemos afirmar que, os colégios particulares apresentavam uma frequencia de 66\% (965 alunos); que as aulas públicas estaduais representavam 24\% (355 alunos) do total e que as aulas municipais atingiam um percentual equivalente a 10\% (136 alunos) do total das aulas organizadas no município de Bagé. Cabe salientar, que na construção destas análises, os dados arrolados acima se referem conjuntamente ao ensino primário e ao ensino secundário.

No processo de análise dos dados quantitativos encontrados nos Relatórios da Instrução Pública do Estado do Rio Grande do Sul entre os anos de 1912 e 1913, sobre a educação municipal, verificamos a permanência do mesmo quadro numérico de escolas encontrado no Relatório Intendencial do ano de 1910, apresentado por José Octavio Gonçalves.

Ademais, no advento da República, os positivistas gaúchos atribuíram à escola um papel modernizador para a nascente sociedade riograndense do século XX, estas apreensões teóricas podem ser apreendidas nos vários documentos encontrados no corpo deste trabalho - Relatórios de Presidentes do Estado, Relatórios Intendenciais, Correspondências oficiais, Decretos e Leis estaduais e municipais - e em autores que pesquisam a história e a história da educação do Estado do Rio Grande do Sul no período da Primeira República.

Neste sentido, as pesquisas revelaram que os discursos dos dirigentes republicanos atribuíram à Instrução Pública um papel fundamental no projeto de desenvolvimento econômico e fundamental na regeneração da sociedade gaúcha.

Na organização da educação pública estadual, segundo os preceitos ideológicos do positivismo gaúcho, os assuntos educacionais transformaram-se ingredientes necessários e fundamentais para a viabilização do projeto republicano de modernização da sociedade rio-grandense.

Na consecução do projeto republicano gaúcho, os positivistas vivenciaram momentos de inflexões e de antagonismos partidários desencadeados pelas querelas políticas entre republicanos e federalistas ocorridos no Estado do Rio Grande do Sul durante a Primeira República, destacam-se neste contexto, a Revolução Federalista (1893), o Congresso Federalista (1917), a Reação Republicana (1922), o Assisismo (1922), o Pacto de Pedras Altas (1923) e por fim, a fundação da Aliança Liberal (1928), todos estes acontecimentos tiveram reflexos e espelhamentos políticos, culturais, sociais, urbanos e educacionais na cidade Bagé.

Autores como Axt (2007), Bakos (1998) e Félix (1987) afirmam que após o período da pacificação do Pacto de Pedras Altas (1923), os acordos políticos garantiram a permanência de Borges de Medeiros no controle político e estatal do Rio Grande do Sul e provocaram uma recomposição das alianças internas do Partido Republicano Rio-Grandense, promovendo assim, um continuísmo político e partidário nos municípios gaúchos.

Em decorrência dos reflexos políticos do Pacto de Pedras Altas e da reorganização interna do Partido Federalista no município de Bagé, o processo eleitoral ocorrido em 1925 levou ao paço municipal, o republicano histórico Carlos Cavalcanti Mangabeira, que representou com maior ênfase a retomada dos princípios positivistas de governar e gerir a sociedade no final da Primeira República na cidade de Bagé. 
Na perspectiva de compreender esta retomada dos princípios positivistas e republicanos tomados após a eleição de Carlos Cavalcanti Mangabeira, analisamos o cenário da Instrução Pública Municipal, desde o início dos anos 1900, da Primeira República no município de Bagé, berço da campanha gaúcha.

Os processos de expansão educacional ocorridos entre os anos de 1900 a 1924 representaram lentamente os primeiros passos para a consolidação do projeto modernizador republicano na cidade de Bagé.

Carlos Cavalcanti Mangabeira ao assumir a Intendência Municipal, no ano de 1925, promoveu discursos de reordenamento da cidade e de vinculação da educação pública na formação e promoção social dos cidadãos bajeenses, estabelecendo as primeiras políticas públicas educacionais de expansão da Instrução e da Educação Pública Municipal.

As fontes examinadas revelaram que no processo da expansão da Instrução Pública Municipal, ocorrido na cidade de Bagé entre os anos de 1925 a 1929, Carlos Cavalcanti Mangabeira imprimiu um novo ritmo administrativo e compôs um novo reordenamento urbano e social para a cidade. Porém, sem dúvida alguma, a maior contribuição de sua gestão administrativa foi à elaboração e estruturação do Sistema Educacional Municipal.

Neste sentido, este processo inaugurado na gestão intendencial de Carlos Mangabeira, possibilitou uma nova organização educacional, produzindo mudanças significativas de ordem administrativa, estrutural, educacional e pedagógica nas questões da Instrução e Educação Pública Municipal.

Para iniciar este projeto de expansão do ensino primário e de mudanças no quadro educacional, a Intendência Municipal estabeleceu primeiramente o Regulamento das Escolas Municipais (1925), que tinha por intenção controlar as questões administrativas e pedagógicas da Educação Primária Pública no município de Bagé, cabe lembrar que estes princípios foram defendidos pelos positivistas gaúchos em todo período da Primeira República.

No esteio deste projeto de expansão educacional na cidade, encontramos ainda, o apoio ao ensino secundário e privado com a municipalização do Gymnasio Nossa Senhora Auxiliadora; a expansão da Instrução Artística com o estabelecimento do Conservatório Municipal de Bagé e a organização da Instrução Física com a construção da Praça de Desportos.

Sendo assim, o projeto educacional de Carlos Cavalcanti Mangabeira se pautou na expansão da educação primária, secundária, artística e física, isto é, na configuração do Sistema Educacional Municipal da Educação Pública

Ao longo do período de 1925 à 1929, o intendente e seu governo demonstrou habilidade política e administrativa, pois, ao vincular à Instrução Primária Pública aos ideais do positivismo e aos preceitos republicanos, justificou que o ensino público e/ou tutelado pelo município -, era o caminho mais rápido no processo da modernização da cidade moderna no contexto da Primeira República.

Sobre a importância do processo que se estabeleceu com a expansão educacional no município de Bagé, Waldemar Amoretty Machado, Inspetor Escolar do município de Bagé, afirma:

Prosseguindo na execução do programma administrativo, a que se produz 0 esclarecido governo de V. S., têm-se empregado todos os recursos accessíveis, para que o ensino [...] tenha a mais ampla diffusão neste municipio. Visando este desideratum, o magisterio municipal, compenetrado da ardua missão que the compete, não se limita a acção passiva de esperar o matriculando, para ministrar-lhe os rudimentos de que carece, mas desenvolvendo sua actividade, vae, por meio de patriotica propaganda, á casa do alumno, realçando a necessidade da instrucção e cooperando deste modo para o augmento da frequencia escolar. [...], mas ainda é uma affirmação do progresso da instrucção neste municipio e constitue um dos melhores títulos demonstrativos dos benefícios, que Bagé vem colhendo, na execução do systema educativo que adoptou. [...] por em equação o problema, para os trabalhos de cada anno, sejam a continuação dos do precedente, seguindo deste modo por caminho recto e seguro ate o fim collimado, o que não só evita 0 
destruir para recomeçar, como ainda facilita as futuras administrações. (grifos nossos) (Relatório Intendencial de 1928, p.33)

Com base neste documento, é possível afirmar que a implantação do Sistema Educacional Municipal foi o caminho para a expansão educacional no município, além de constatar que o papel educacional-pedagógico dos professores é imprescindível na formação do indivíduo na sociedade republicana.

Afinal, a educação foi a melhor forma encontrada pelos positivistas republicanos para preconizar os ideais, os símbolos, as crenças, os rituais e os valores da República. Logo, constata-se que as ações empreendidas pela gestão de Carlos Cavalcanti Mangabeira revelaram todas estas particularidades no fazer educacional na cidade de Bagé no final da Primeira República.

Para Gramsci (1978), a categoria intelectual auxilia a entender a formação da sociedade moderna, devido ao fato de ser por intermédio do lugar ocupado por esses sujeitos que chegaríamos à compreensão geral das relações de poder e de dominação de determinados grupos. Portanto:

\begin{abstract}
A escola é o instrumento para elaborar os intelectuais de diversos níveis. A complexidade da função intelectual nos vários Estados pode ser objetivamente medida pela quantidade das escolas especializadas e pala sua hierarquização: quanto mais extensa for a "área" escolar e quanto mais numerosa forem os "graus" "verticais" da escola, tão mais complexo será o mundo da cultura, a civilização, de um determinado Estado. (GRAMSCI, 1978, p. 09).
\end{abstract}

Enfim, a maior herança educacional de Carlos Cavalcanti Mangabeira como Intendente Municipal deBagé entre os anos de 1925 a 1929, foi o estabelecimento do processo da expansão da educação propagado pelo primeiro Sistema Educacional de Ensino do município de Bagé.

Mangabeira encontrou na Instrução Primária Pública a possibilidade de vincular os ideais do positivismo e os preceitos republicanos da educação pública, demonstrando que o ensino era o caminho mais viável e rápido no processo de civilizar o povo e de modernizar a nação.

Ademais, neste processo promoveram-se várias reformas na Instrução Pública Municipal, tais como, a normatização da educação municipal, a municipalização do Gymnasio Nossa Senhora Auxiliadora, a encampação municipal da Escola de Música e a construção da Praça de Desportos, um templo dedicado a conjugação de todos os discursos republicanos presentes na Primeira República gaúcha.

Afinal, a educação foi à melhor forma e/ou caminho encontrado pelos positivistas para preconizar os símbolos, as crenças, os rituais e os valores da República, e, além disso, foram especialmente a partir do governo de Carlos Cavalcanti Mangabeira que se manifestaram todas estas possibilidades na campanha gaúcha e na Rainha da Fronteira, reafirmando a ideia de que a Educação Positivista Republica representou o pensamento social e hegemônico de uma época histórica, que deixou importantes traços culturais e heranças patrimoniais para a sociedade bageense nas primeiras décadas do século XX.

\section{Referências}

AXT, Gunter. Coronelismo Indomável: o sistema de relações de poder. In: História Geral do Rio Grande do Sul (1889-1930). 1a Ed. Passo Fundo: Méritos, 2007. v. 3, República Velha (1889-1930). Tomo I.

AZEVEDO, Janete M. L. A educação como política pública. Campinas, SP: Autores Associados,1997.

BAKOS, Margaret M. Marcas do positivismo no governo municipal de Porto Alegre. Revista Estudos Avançados. [online]. 1998, vol.12, no 33, pp. 213-226.

CARBONI, Florence; MAESTRI, Mário (org.) Raízes italianas no Rio Grande do Sul (1875-1987). Passo Fundo: UPF, 2000.

CHUVA, Márcia. O ofício do historiador: sobre ética e patrimônio cultural. In: INSTITUTO DO PATRIMONIO HISTÓRICO E ARTÍSTICO NACIONAL. Anais da I oficina de Pesquisa: a pesquisa histórica no IPHAN. Rio de Janeiro: IPHAN, Copedoc, 2008. 
CONDERCET, M. J. A. N. Cinco memorias sobre la instrucción pública e otros escritos. Madrid: Morata, 2011

CORSETTI, Berenice. Controle e Ufanismo. A Escola Pública no Rio Grande do Sul (1890-1930). Santa Maria: UFSM, 1998. Tese (Doutorado em Educação), Faculdade de Educação, Universidade Federal de Santa Maria, 1998.

Cultura política positivista e educação no Rio Grande do Sul/Brasil (1889/1930). In: Cadernos de Educação - FaE/PPGE/UFPel - Pelotas, no 31, julho/dezembro 2008.

FÉLIX, Loiva Otero. Coronelismo, borgismo e cooptação política. Porto Alegre: Mercado Aberto, 1987.

GRAMSCI, A.Os intelectuais e a organização da cultura. Rio de Janeiro: Civilização Brasileira, 1978.

GUTFREIND, leda. Historiografia sul-rio-grandense e o positivismo comtiano. 1998, p. 50. In: GRAEBIN, Cleusa M.; LEAL, Elisabete (org.). Revisitando o positivismo. $1^{\underline{a}}$ ed. Canoas: Editora La Salle, 1998, p. 47-58.

LUZURIAGA, L. História da educação pública. São Paulo: Editora Nacional, 1959.

MAGALHÃES, Justino Pereira de.A construção de um município pedagógico - o caso de Vimioso. Lisboa: Universidade de Lisboa, 2004 (mimeo).

NAGLE, Jorge. Educação e Sociedade na Primeira República. - 2. ed. - Rio de Janeiro: DP\&A, 2001.

Rodríguez, Ricardo Vélez. Castilhismo: Uma Filosofia da República. Brasília: Senado Federal, Conselho Editorial, 2000. (Coleção 500 anos).

- O castilhismo e as outras ideologias: In: Golin, Tau; Boeira, Nelson (Org). História do Rio Grande do Sul. Passo Fundo: Méritos, 2007, v. 3, Tomo I.

SAVIANI, Dermeval. Educação brasileira: estrutura e sistema. - 5ª Ed. São Paulo: Editora Saraiva, 1983.

Educação: do senso comum à consciência filosófica. 7. ed. São Paulo: Cortez, 1986.

História das Idéias Pedagógicas no Brasil. 2 ed. rev. e ampl. . Campinas: SP: Autores Associados, 2008. (Coleção memória da educação).

Sistema de Educação: Subsídios para a Conferência Nacional de Educação. 2010. Disponível em:

http://portais.seed.se.gov.br/sistemas/portal/arquivos/ p14-499_conae_dermevalsaviani.pdf. Acessado em 06/06/2013.

TAMBARA, Elomar. A Educação no Rio Grande do Sul sob o Castilhismo. Porto Alegre, Universidade
Federal do Rio Grande do Sul, Programa de Pós Graduação em Educação, 1991. Tese de Doutorado.

As Metamorfoses do Professorado Gaúcho ao final da República Velha. In: II Seminário de Pesquisa em Educação - Região Sul (Anped Sul). Curitiba/PR: UFPR, 1999. Disponível em: http://www.portalanpedsul.com.br/admin/uploads/199 9/Historia Da Educacao/Trabalho/05 3325 AS ME TAMORFOSES DO PROFESSORADO GAUCHO AO FINAL DA REPUBLICA VELHA NO RIO GRA NDE DO SUL.pdf. Acesso em 08/06/2013 